Chapter 17

\title{
Fränkel Functional Regulator in Early Treatment of Skeletal Distal and Mesial Bite
}

\author{
Zorana Stamenković and Vanja Raičković \\ Additional information is available at the end of the chapter \\ http://dx.doi.org/10.5772/59228
}

\section{Introduction}

Skeletal distal and mesial bite are irregularities in sagittal direction. During treatment of these malocclusions we want to achieve correct occlusion and morphology, right implementation of all orofacial functions and good facial aesthetics. If we start with orthodontic treatment in early mixed dentition we can expect good and stabile therapeutic results and we can prevent later developmental problems. This way, we avoid treatment with fixed appliances in permanent dentition and orthognatic surgery after the end of growth. It is important given the fact that orthodontic treatment is very expensive.

Etiology of skeletal distal and mesial bite are heredity and some exogenous etiologic factors. These malocclusions are inherited polygenically. Skeletal distal bite is often present among the members of the same family and among twins. Other general etiological factors are Pierre Robin syndrome, syndrome of hemifacial microsomia and endocrine disorders. Local etiological factors, are, mostly, bad habits, in the age after the third year of life. The most important bad habit is thumb sucking, which causes protrusion of the upper and retrusion of the lower incisors and increasing of overjet. Skelatal distal bite is one of symptoms in CMD, as a result of ankylosis and trauma of TMJ. Dodic [1] found that $79.9 \%$ patients with skeletal class II has positive index of CMD. Etiology of skeletal mesial bite are heredity, some specific factors, functional effects, trauma and environmental factors [2]. Previously it was thought that this malocclusion was inherited as an autosomal dominant trait. Accordingly there is the existence of the so-called Habsburgs mandible. Many members of the Habsburg monarchy had a typical large lower jaw and skeletal mesial bite [3]. If in a family exists severe skeletal Class III in 33\% of their children will appear Class III and in $17 \%$ of their siblings. Some scientific studies find that there is a gene which is related to mandibular prognathism. There is different expressivity of genes in specific types 
of progeny. Different genetic locus are responsible for the definitive form of the lower jaw. Other local etiologic factors are enlarged tonsils, breathing through the mouth and early extraction of deciduous molars. Patients with cleft lip and palate and some syndromes (Apert, Crouzon) often have mesial bite due to insufficient growth of the upper jaw.

Skeletal distal bite is most common in white population (38\%), two times more frequent than in members of black race(20\%), while frequency of this malloclusion in yellow race is $10-15 \%$. The frequency of skeletal distal bite decreases with age, from $25-30 \%$ in mixed dentition, $20-25 \%$ in early permanent dentition to $15-20 \%$ in adult population [4]. Mesial bite commonly occurs among members of the yellow race with a frequency of $4 \%$ to $14 \%$ because they have underdeveloped nasomaxillary complex and deficient growth of the upper jaw. In the black population frequency of mesial bite is between $5 \%$ and $8 \%$, while in the white population frequency of this malocclusion is from $1 \%$ to $4 \%$. Frequency of malocclusion increases during the time. Skeletal mesial bite occurs in $23 \%$ in deciduous dentition, $30 \%$ in mixed dentition and $34 \%$ in permanent dentition.

\section{Aim}

The aim of this investigation was to compare clinical effects of different mobile orthodontic appliances (active and functional) in early treatment of skeletal distal (Class II division 1) and mesial (pseudo Class III) bite.

\section{Material and method}

In this study 60 patients were included with skeletal distal bite caused by mandibular retrognatism. All patients with this malocclusion had increasing value of angle ANB $\left(>4^{\circ}\right)$, due to the decrease of angle SNB $\left(<80^{\circ}\right)$. Main clinical characteristics of skeletal distal bite caused by mandibular retrognatism are: convexity of facial profile with distal position of the lower lip and chin and protrusion of the upper lip, distal relationship of dental arch and jaw bases, protrusion of the upper incisors and retrusion of the lower incisors with increasing value of overjet, inserting of the lower lip between upper and lower incisors, passing of the upper and lower incisors during eruption and their supraposition, traumatic deep bite, short mandibular corpus and lower dental arch, narrow and elongated upper dental arch, expressed mentolabial and nasolabial sulcus, shortened lower third of face and retroinclination of the lower jaw. Clinical effects were analysed on 60 patients with skeletal distal bite, without earlier orthodontic treatment. Patients were divided in three groups, with 20 patients in each. First group was treated with FR-I, second with bionator by Balters type I and the third group with Hotz mobile appliance. Effects were determined on study casts and lateral cephalometrics before and after treatment, and during functional clinical examinations and analysis of facial aesthetics.

Also, in this study were included 40 patients with skeletal Class III caused by maxillary retrognatism. They have typical changes in facial aesthetic and profile. All patients had 
decreasing value of angle ANB $\left(<2^{\circ}\right)$, due do decrease of angle SNA $\left(<82^{\circ}\right)$. Main clinical characteristics of pseudo Class III (caused by maxillary retrognatism) are: concavity of the facial profile with distal position of the upper lip and correct position of the lower lip and chin, mesial relationship of dental arches and jaw bases, normoinclination of upper and lower incisors, narrow and short upper dental arch, reverse overjet, lateral cross bite, underdeveloped nasomaxillary complex, crowding in upper dental arch, anteinclination of the upper jaw and changes in vertical direction. In this group of patients, also, study casts and profile teleradiograms have been analysed before and after orthodontic treatment.

Growth modification is possible if we start with orthodontic treatment early enough, before pubertal growth acceleration. Ideal period for growth modification is early mixed dentition. In this period we can affect the size and position of upper and lower jaw and their relationship. In girls treatment should be initiated at an earlier age than in boys, approximately two years. In girls "juvenile acceleration" starts 1-2 years before pubertal growth acceleration. Overall growth is affected by age, constitution, seasonal and cultural factors. Before orthodontic treatment it is necessary to determine skeletal maturity of our patients [5]. Treatment with growth modification is possible when patient is in one of three first stage of skeletal maturation (Fig. 1).

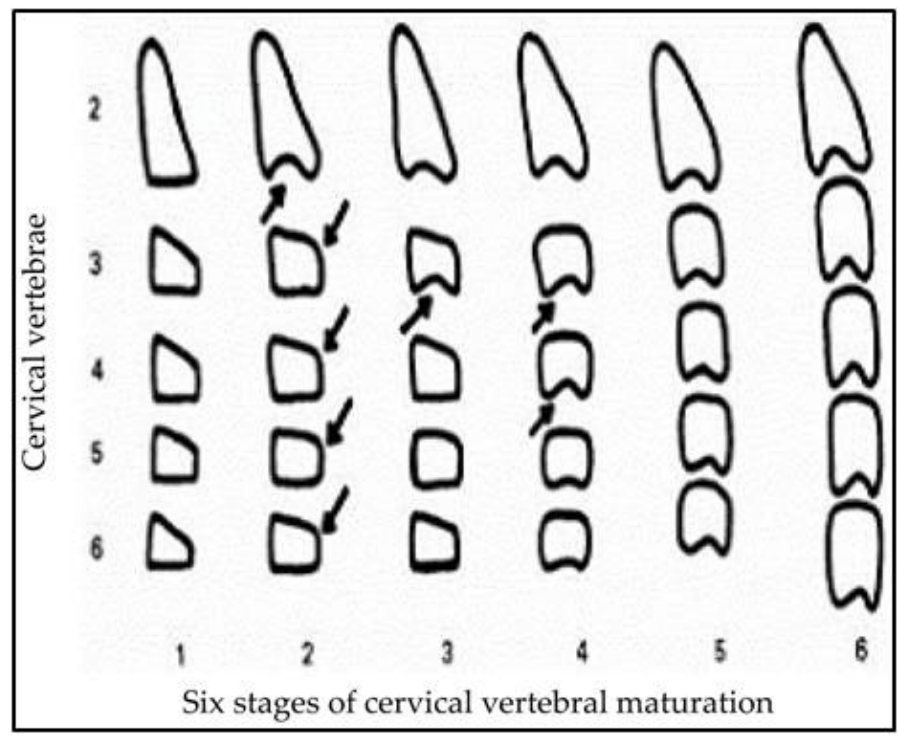

Figure 1. Six stages of cervical vertebral maturation (O'Relly \& Yanneillo, 1988).

When we make decisions about growth modification treatment we need to know the degree of discrepancy between viscerocranium and neurocranium, age and sex of the patient, external and internal motivation, which appliances we want to use, at what stage of skeletal maturation is patient and how much growth left to the end of maturity [6, 7]. 


\section{Treatment of skeletal distal bite}

In modern orthodontics treatment of skeletal distal bite can be performed using many dental worn functional appliances, such as activator, bionator by Balters, twin block, Herbst appliance, Hotz appliance and vestibular plate. These appliances rest on teeth and they stimulate growth of the lower jaw due to changes in activity of orofacial muscles.

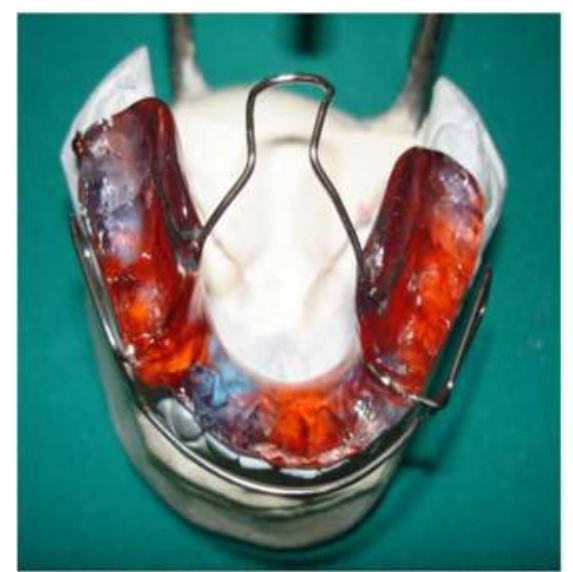

(a)

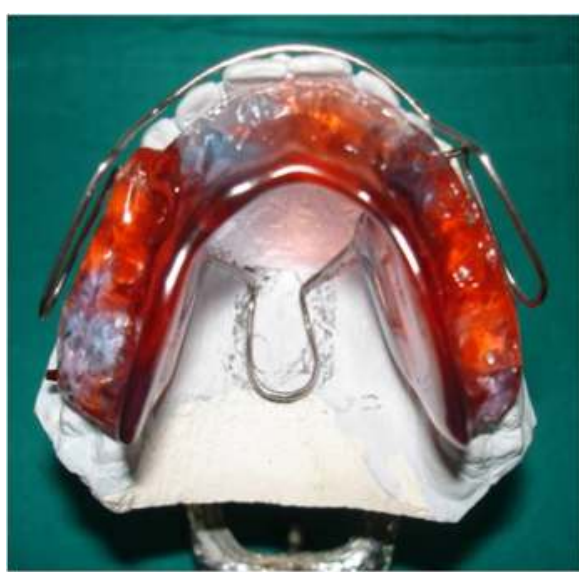

(b)

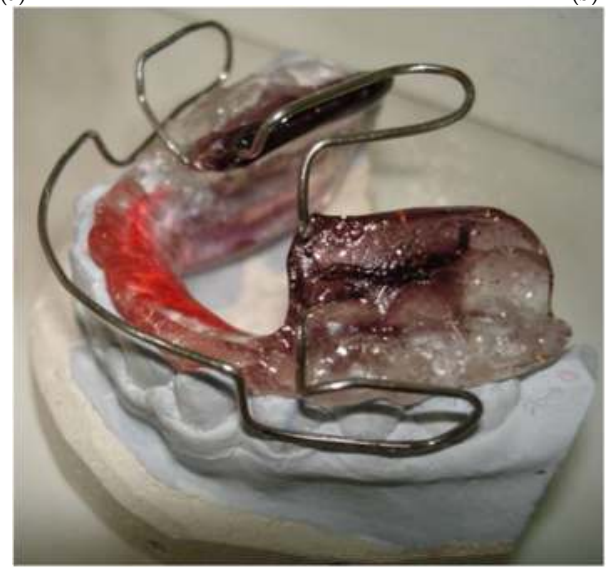

(c)

Figure 2. a.,b.,c. Balters bionator type I

To Balters opinion distrurbed function, size and tone of tongue are the main cause of all malocclusions. Bionator was designed and used in orthodontic practice by Balters in Germany (1950.). Bionator by Balters type I or the standard form is used in treatment of skeletal distal bite. This appliance is known in literature as reduced activator with interoclusal acrylic. 
Components of this appliance are palatal arch directed pharyngeal, vestibular arch above upper incisors and buccal loops in the area of canines (Fig 2.a.,2.b.,2.c.). Construction bite is determined and taken in incisal relationship of incisors without activation in vertical direction. Skeletal effects are increasing of mandibular corpus and ramus, anterior displacement of the lower jaw, increasing value of angle SNB and decreasing value of angle ANB $[8,9,10]$.

Hotz appliance is modified active mobile orthodontic appliance. This appliance in orthodontic practice was introduced by Hotz (1966.) in Germany. Appliance has angular frontal bite plane (Fig.3.). This appliance causes growth modification and anterior growth of the lower jaw in patients with forward facial rotation. It is necessary that inclined frontal bite plane has sufficient length for anterior movement and sliding of the lower jaw [11]. Skeletal effects are stimulation of saggital growth of the lower jaw and anterior displacement. Dental effects are retrusion of the upper and protrusion of the lower incisors and extrusion of the posterior teeth [12].

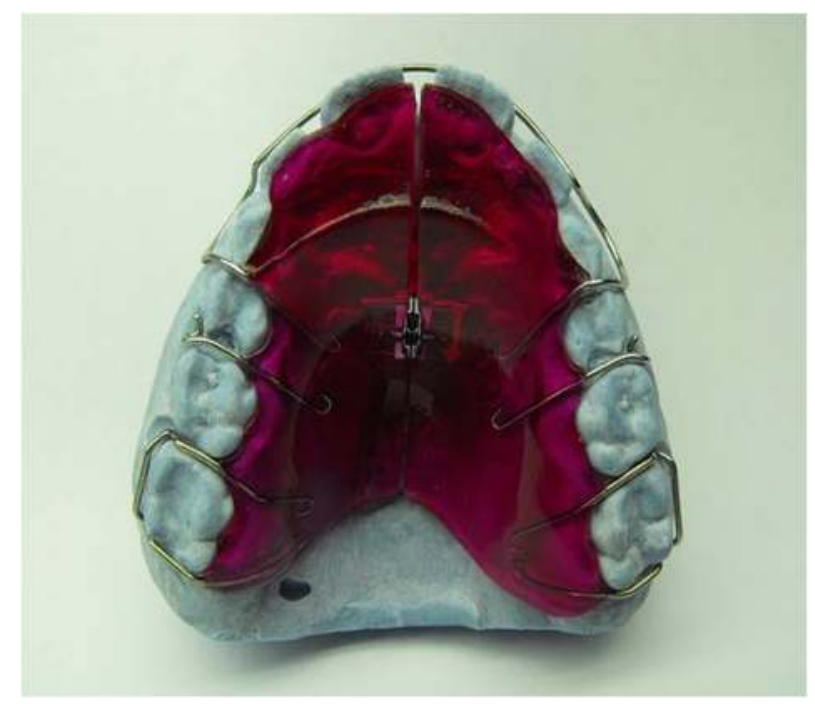

Figure 3. Hotz appliance

\section{Fränkel appliance type I (FR-I)}

Fränkel functional regulator (FR) is only mounted functional appliance which can effectively correct morphological (skeletal and dental) and functional irregularities. It works by pressure application at skeletal and dental structures, elimination of the pressure surrounding perioral musculature and causing tensile stress in the area of mucosal fornix, where exist bone apposition. Construction of this appliance was suggested by Rölf Fränkel in Germany (1966.) 
[13]. During time the position of the lower jaw permanently changed without affecting the position of the teeth. The essential changes are tissue changes at the articular zone of growth. This appliance significantly changed muscles activity and whole physiological state of orofacial complex. There are early and late treatment of skeletal distal bite using FR-I. Early treatment begins in the age of 7-8 years, in early mixed dentition, after eruption of first permanent molars and incisors. Late treatmen starts in the age of 12 years (average) after eruption of canines and premolars [14]. Whole treatment contains active and retention period. Active period lasts an average of 18 to 24 months. During this period patient wears appliance continuously during the day, except during meals. Retention period lasts, also, 24 months. During this period patient wears appliance only at night. After 6 months of treatment sagittal relationship was corrected for half a molar width.

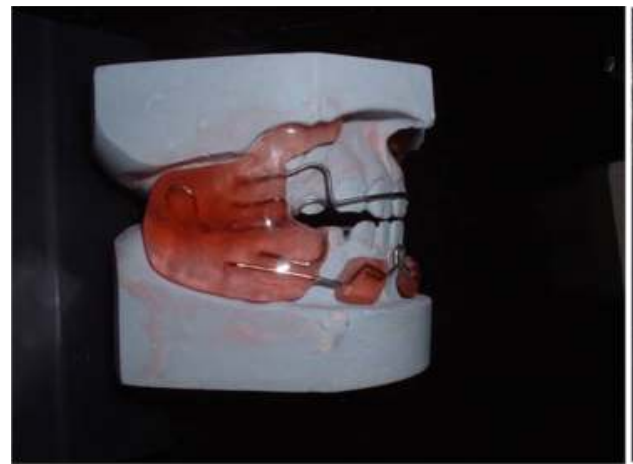

(a)

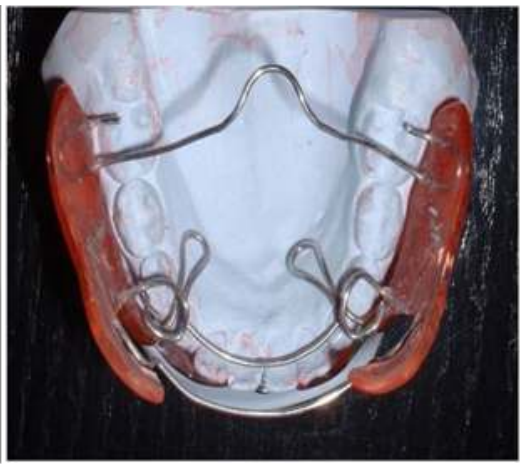

(b)

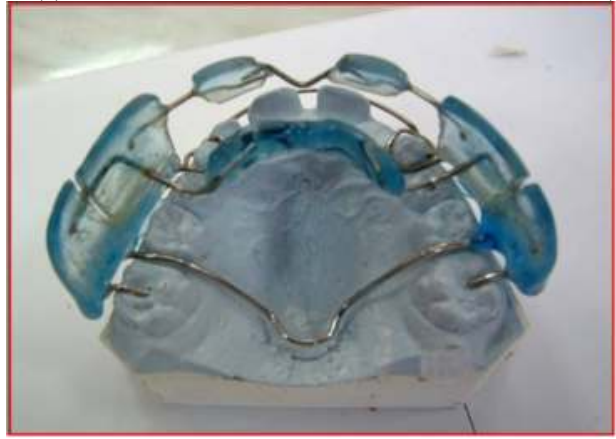

(c)

Figure 4. a.,b.,c. Fränkel appliance type I (FR-I)

In treatment of skeletal Class II we use three type of FR-I (Ia, Ib, Ic). FR-Ia is indicated for use in cases with: skeletal Class I with deep bite, skeletal Class I with protrusion of the upper and retrusion of the lower incisors, skeletal Class I with apical crowding, bilateral crossbite, skeletal Class II division 1 with overjet less than $5 \mathrm{~mm}$, skeletal Class II divison 1 with deep bite and retrusion of the lower incisors. FR-Ib is indicated in patients with skelelat Class II divison 1 
and overjet between $5 \mathrm{~mm}$ and $7 \mathrm{~mm}$ and skeletal Class II divison 1. with deep bite. FR-Ic is indicated for use in cases with severe skeletal Class II divison 1 and overjet over $7 \mathrm{~mm}$, skeletal Class II with deep bite and difficulties to establish contact between lips during anterior movement of the lower jaw. Components of this appliance (FR-Ia) are: lateral acrilyc shields, pelotas for lower lip, labial arch, linqual arch, palatal arch with anchorage on the upper first molars and loops for upper canines (Fig. 4a.,b.,c.). For construction and making of this appliance is necessary construction bite in incisal relation of incisors without activation in vertical direction (Fig.5.). FR-Ib besides these elements includes linqual shield with linqual arch and additional arch for protrusion of the lower incisors. For FR-Ic we determine and take construction bite in relation of Class I on posterior teeth. This appliance has screw for compensatory anterior movement of the lower jaw. Construction and design of this appliance is very gentle, so patients should be very careful during manipulation with it [15].

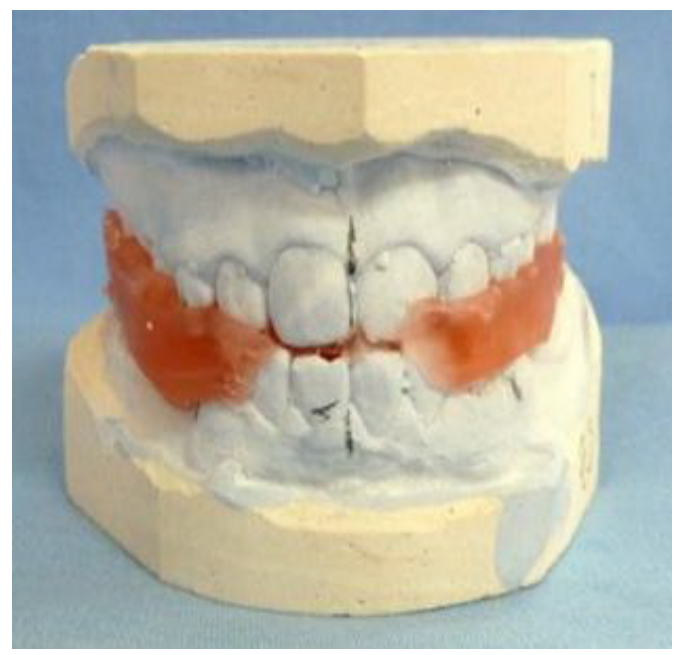

Figure 5. Construction bite for FR-I

\section{Treatment of skeletal Class III}

Skeletal Class III can be treated by many different dental worn functional appliances. Representatives of this group of appliances are activator, bionator by Balters type III, orthopedic bionator, chin cup, Y appliance, appliance with Bertoni screw and facial mask. The only representative of tissue worn appliances is FR-III. In older age surgical treatment is indicated in combination with fixed appliances [16].

Clinical effects were determined on 40 patients with skeletal Class III caused by maxillary retrognatism (angle $\mathrm{SNA}<82^{\circ}$, angle $\mathrm{ANB}<2^{\circ}$ ). None of the patients have previously had an orthodontic treatment, all of them were in period of early mixed dentition, after eruption of 
first permanent molars. These patients were divided in two groups, with 20 patients in each. Patients in the first group were treated by FR-III, while patients in the second group were treated by Y appliance. Clinical effects were analyzed on study casts, lateral cephalometric and facial aesthetic before and after treatment. Separately were analyzed and interpreted parameters of position and development of the upper and lower jaw, parameters of intermaxillary relations, parameters of the facial growth, the cranial base parameters, parameters of the position of the incisors, parameters of TMJ, soft tissue profile parameters, parameters of skeletal and dental changes during the treatment and methods of investigation of orofacial functions.

$\mathrm{Y}$ appliance is active, mobile orthodontic appliance. This appliance has acrylic plate cut to shape letter $Y$ with two screws in the area of canine (Fig.6.). Patients turn both screws in the same time, that way the appliance causes protrusion of the upper incisors. Y appliance is useful in patients with pseudo Class III [12]. With this appliance we correct reverse overjet and eliminate premature contact with stabile treatment result. Ideal time for treatment is period of mixed dentition. Patients turn screws once in 7 days, with biological movement less than $1 \mathrm{~mm}$ during one month. During retention period patient wear appliance only during the night, without turning the screws.

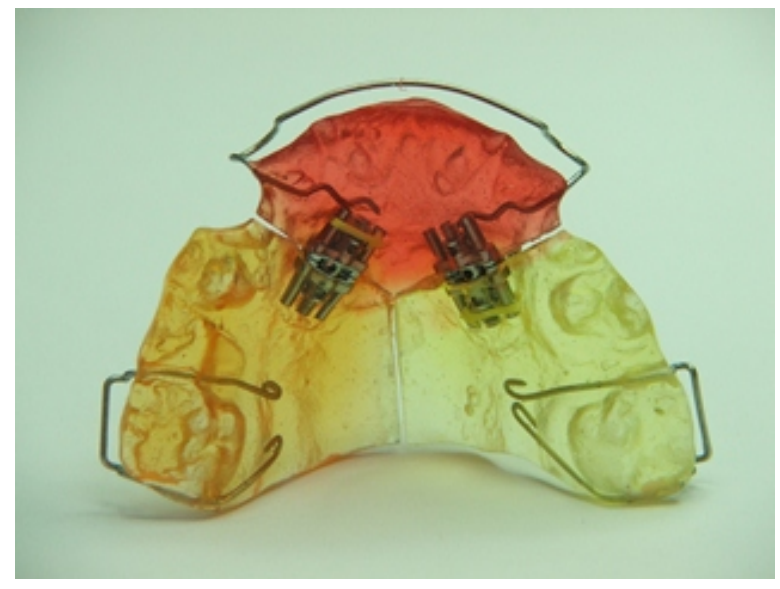

Figure 6. Y appliance

\section{Fränkel appliance type III - (FR-III)}

Fränkel functional regulator (FR) is passive, mobile functional appliance. At the same time it is the only tissue worn functional appliance. With FR we can correct both occlusal (dental and skeletal) and functional irregularities. Three main mechanisms of action of this device are: aplication of pressure, elimination of pressure and application of pulling force. Rölf Fränkel 
presented this appliance to orthodontic public in Germany in 1966. Application of pressure prevents excessive growth of the lower jaw in sagittal direction. Elimination of pressure separates the soft tissues of the lips and cheeks and prevents their contact with dentoalveolar structures. FR-III contributes to the proper formation of dentoalveolar structures of the upper and lower jaw. Application of pulling force increases the activity of osteoblasts in the periost, that way appliance contributes to the creation of new bone tissue in the upper jaw [17]. Acrylic pelotas are located in the upper vestibule and stimulate the sagittal growth of the upper jaw. FR-III causes tissue changes in the articular zone of growth. During wearing of appliance there is a continual activation of the muscles of the orofacial region to change their tone and activity. Optimal time for treatment with this appliance is early mixed dentition, immediately after eruption of all upper permanent molars, at an age of about seven years of age. The best therapeutic results are expected in patients with reverse overjet $(4-5 \mathrm{~mm})$. The whole therapeutic procedure contains active and retention phase. Active phase lasts 24 to 30 months. During this active period, patients wear FR-III continuosly during the day and night, except during meals. Retention phase lasts about 24 months. During retention period, patients wear appliance only at night. This phase is important to preserve the stabile therapeutic results. From this we can conclude that the total duration of therapy is quite long. Patients can easily get used to this appliance, it is comfortable to use, they are motivated for treatment and we expect full cooperation with them and their parents. In treatment of skeletal Class III we use Fränkel functional regulator type III (FR-III). There are two different types, type FR-IIIa and type FR-IIIb. Type FR-IIIa is indicated in early mixed dentition in patients with pseudo mesial byte and deep reverse overjet. Type FR-IIIb is indicated in early mixed dentition in patients with pseudo mesial byte, but without deep reverse overjet. Contraindications for treatment with FR-III are: late age of patients, skeletal Class III caused by mandibular prognatism, severe teeth rotation and malpositions and coronary crowding. FR-IIIa consists of: two lateral vestibular acrylic shields, pelotas for upper lip, lower labial arch, bilatteral posterior acrylic plate on teeth, wire anchorage on the lower first permanent molars, palatal arch with protrusion arch in the upper jaw and wire elements between pelotas and shileds (Fig. 7a.,b.,c.). FRIIIb has simillar construction. The only difference is that FR-III does not have bilatteral posterior acrylic plate on teeth, because it is indicated in cases without deep reverse overjet, and in this situation desarticulation is not necessary. Construction and design of this appliance are very delicate. That is why patients must be very careful and patient during wearing and manipulation with FR-III. The most important phase in the development of this device is taking an accurate construction bite. Construction bite determines the position of the lower jaw in all directions. For this appliance construction bite is taken in maximal retrusion of the lower jaw, with proper midline alignment of the upper and lower jaw. The ideal would be to provide edge to edge contacts between upper and lower incisors in sagittal direction. Activation in vertical direction depends of depth of reverse overjet. In cases with deep reverse overjet, construction bite is taken with vertical activation of $2-4 \mathrm{~mm}$ above the physiologic rest position. If patients do not have deep reverse overjet, construction bite is taken without activation in vertical direction, at physiologic rest position. Design of appliance enables correct teeth eruption with elimination of irregular muscle activity. It is said that appliance causes oral 
gymnastics. Pelotas stimulate growth of the upper jaw and cause increase of the width of apical base. Pelotas have triple effect: elimination of the pressure of the upper lip to the sagittal underdeveloped upper jaw, creating tensile stress in the vestibule and stimulate osteoblasts activity at the level of the periost and directing the force of the upper lip to the lower jaw over the lower vestibular arch, thus resulting in retrusion Acrylic lateral shields are in contact with lower teeth and apical base, while settle $3 \mathrm{~mm}$ of dentoalveolar structures of the upper jaw. Appliance then stimulates both, transversal and sagittal growth of underdevolped maxilla. Fränkel suggests that functional disorder is result of malocclusion, and rarely is the primary cause of the irregularities. Appliance stimulates proper orofacial functions and achieves a balance between the muscles of tongue and buccal muscles. It eliminates the disturbed functions due to activation and adaptation of muscles. It is important to wear the appliance during the day because it achieves a constant muscle activity, while the activity is significantly reduced during the night. It is necessary to examine the relationship between form and function if we want a successful therapeutic result. FR-III regulates the function of swallowing due to buccal shields. These shields eliminate the pressure of buccal muscles and allow extension of dentoalveolar structures by changing the position and functions of tongue during swallowing. This provides a transition from infantile to mature swallowing. In some patients function of tongue is changed due to adaptation to the existing malocclusion, while in other groups of patients that is the primary cause of malocclusion. FR-III significantly increases anterior and posterior width in the upper and lower jaw and length of the upper dental arch. Appliance decreases buccal inclination of the upper first permanent molar. With FR-III dental arch can expand for $6 \mathrm{~mm}$ and alveolar base for $5 \mathrm{~mm}$. Palatal arch allows expansion of lateral shields, gives support to appliance and contributes to transverse anchorage of appliance. Palatal arch is $0.5 \mathrm{~mm}$ from the mucosae. Protrusion arch has function to cause protrusion of the upper frontal teeth. Active arch is in contact with palatal surfaces of upper incisors, close to incisal edge. Therefore, arch causes protrusion of incisors without influencing their vertical eruption. Pelotas have a parallelogram shape with rounded corners. Lower edge of pelotas is located deeply in the vestibule, $2.5-3 \mathrm{~mm}$ from mucosa and $7-8 \mathrm{~mm}$ from gingival edge. Upper edge of pelotas is $5 \mathrm{~mm}$ from marginal gingival edge. The appliance does not rely on the posterior teeth in the upper jaw, because in that case pelotas cause distal movement of upper posterior teeth $[13,14]$. Phases in treatment and creating of FR-III are: clinical examination, functional analysis, impressions of upper and lower jaw for study casts, analysis of lateral cephalograms and orthopantomograms, construction bite, preparation of study casts, definite preparation in the laboratory, giving the appliance to the patient and regular check-ups every four to six weeks. Phase of adaptation to FR-III is longer than with the other functional appliances. A common protocol is that patient wears the appliance for 2 hours a day for first two weeks of therapy. Next two weeks the appliance is worn for 4 hours a day. At the next check-up the appliance wearing time extends to 6 hours a day in combination with speech exercise. After the third control check-up, it is recommended to wear the appliance at all times for 24 hours, except during meals. After three months of properly wearing of appliance changes in sagittal, vertical and transversal direction are observed. Generally, after six months of treatment, skeletal Class III is corrected for half a premolar width. If there is lateral open bite 
it is a sign of good cooperation of the patient, because the changes in the vertical plane are more slowly than in the transversal and vertical direction, and eruption of the lower posterior teeth happens later.
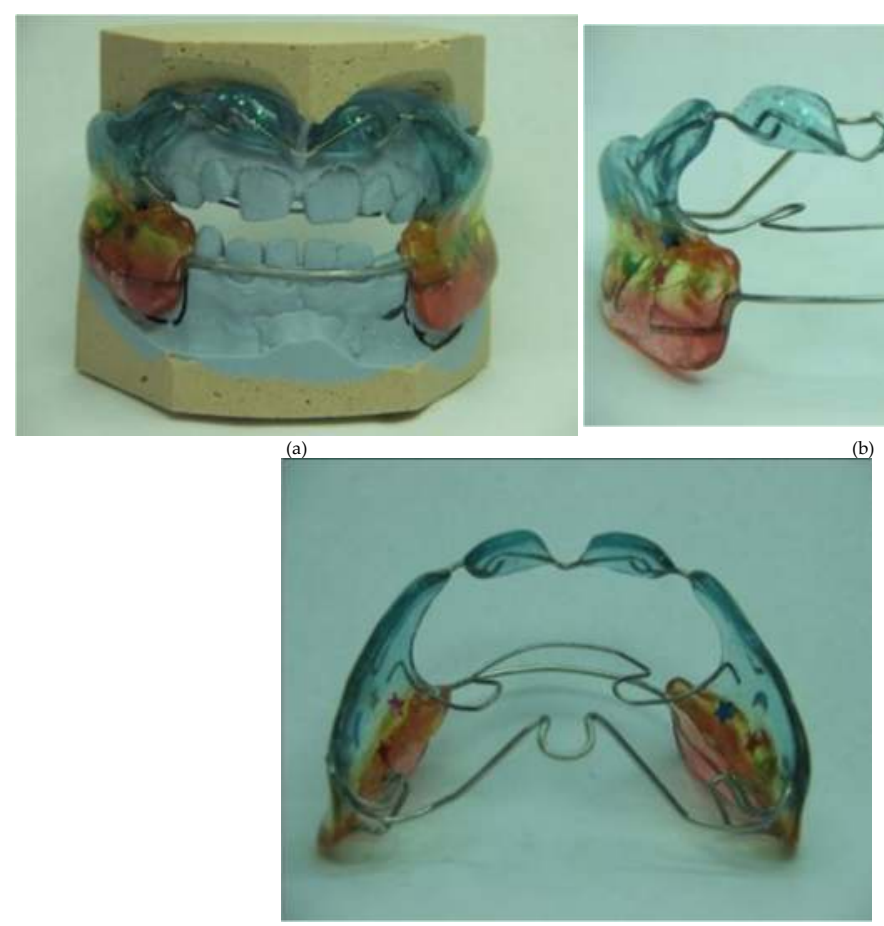

(c)

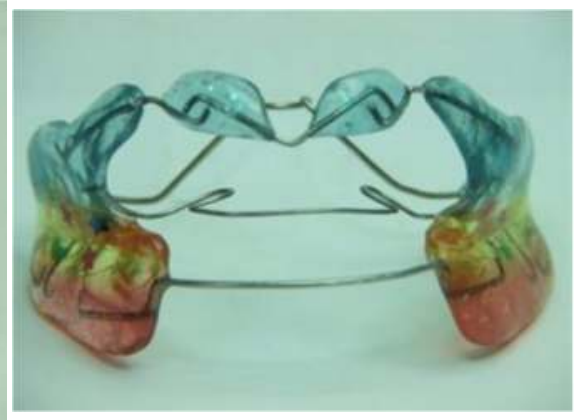

Figure 7. a.,b.,c. Fränkel appliance type III (FR-III)

\section{Results and discusion}

\subsection{Comparative analysis of the FR-I appliance, bionator by Balters and Hotz appliance treatment effects}

Position and development of the upper jaw were analyzed using values of angles SNA, $\mathrm{SN} / \mathrm{SpP}$ and J and linear distance which determines length of maxillary corpus. All used appliances didn't have significant impact on position of the upper jaw. Their effects were directed to the lower jaw. Changes on the lower jaw were determined using values of angles SNB, SN/MP and SNPg and linear distances of length of mandibular corpus, total length of lower jaw, height and width of mandibular ramus. All appliances significantly changed sagittal position of the lower jaw [18]. The most pronounced increase of angle SNB causes FR- 
I from $74.70^{\circ}$ to $77.65^{\circ}\left(\mathrm{p}=0.001^{*}\right)$. FR-I and bionator by Balters type I cause reducing of vertical inclination of the lower jaw to the anterior cranial base, while Hotz appliance causes increasing of vertical inclination of the lower jaw. Analysis of linear parameters showed mandibular growth in all directions, especially during the application of FR-I. Length of mandibular corpus increased from $71.22 \mathrm{~mm}$ to $73.20 \mathrm{~mm}$. Malocclusion was corrected due to the joint effect of the pubertal growth process and appliances effects. All effects of appliances resulting in anterior displacement of the lower jaw and chin, with increasing value of angle SNB, without affecting the total amount of growth. In some cases existed inhibition of sagittal growth of the upper jaw, resulting in better relation between jaw bases [19, 20,21].

Interjaw relationship was analyzed using values of angles ANB (sagittal interjaw angle), B (basal angle-vertical interjaw angle), SpP/OcCP (inclination between upper jaw and occlusal plane) and $\mathrm{MP} / \mathrm{OcCP}$ (inclination between lower jaw and occlusal plane). All appliances caused the correction of skeletal Class II with decreasing values of ANB angle from $6.60^{\circ}$ to $3.60^{\circ}$ ( $p<0.001$ FR-I), $5.90^{\circ}$ na $4.90^{\circ}$ ( $p=0.001$ bionator by Balters type I), $5.80^{\circ}$ to $5.10^{\circ}(p=0.032$ Hotz appliance). Skeletal effect was greater in the younger age. After that age, in permanent dentition, dental effects were dominant. FR-I changed function and activity of orofacial muscles and caused their transformation [22].When appliance is in the mouth vestibular pelotas provide anterior movement of the lower jaw. " $U$ " loop prevents distal movement of the lower jaw in initial position. It is necessary to provide at the same time growth stimulation of the lower jaw and adaptation of soft tissues. This is the only way therapeutic result can be stabile and long-term. It is suggested to provide neutroocclusion through several phases, with gradually mesial movement of the lower jaw, using construction bite.

FR-I decreased basal angle, while bionator by Balters type I and Hotz appliance ( $\mathrm{p}=0.044$ ) increased value of this angle. These appliances are contraindicated in patients with backward facial rotation, because the use of this appliance would result in opening of the bite and divergent growth of jaw bases [23]. All used appliances increased vertical inclination of the upper jaw to the occlusal plane, without statistical significance. FR-I indicated anteinclination of the lower jaw to the occlusal plane, while Hotz appliance and bionator by Balters type I caused retroinclination of the lower jaw. Hotz appliance caused extrusion of posterior teeth, which reduced overbite and contributed to the opening of the bite. These changes are consequence of movement of fossa glenoidalis during growth.

All used appliances increased values of angles NSAr and ArGoMe, while FR-I and Hotz appliance increased value of angle SArGo, but bionator by Balters type I decreased value of this angle. Sum of angles of Björk polygon were increased, most evident when using FR-I, from $393.55^{\circ}$ to $395.70^{\circ}$. Mostly, patients in this sample had forward rotation before beginning of the orthodontic treatment. It was good prognostic sign for patients with skeletal Class II, while vertical growth was not significant in cases with mandibular retrognathism. If we start with orthodontic treatment early enough (in early mixed dentition) we can change type of facial growth [24, 25]. FR-I and bionator by Balters mostly didn't change type of facial growth, while Hotz appliance caused backward rotation and vertical facial growth. During therapeutic procedure anterior and posterior facial height were decreased, partially as a consequence of intensive growth in this age and as a result of used appliances. Simillar changes were registred 
on both, anterior and posterior facial height, but facial growth in total was not changed during this period. Both methods, Björk and Jarabak, are metric, static and they show type of facial growth in one moment. That's why these methods are not reliable for long-term research.

Changes on the cranial base were analyzed by linear distances N-S (length of anterior cranial base), S-Ba (length of posterior cranial base) and N-Ba (total length of cranial base) and angle of cranial base NSBa. All parameters were increased during orthodontic treatment. Changes in linear distances were not statistically significant during this period. Thereby distance N-Se can be used as a reference plane for superposition of lateral cephalometrics for longitudinal studies. Changes in linear distances were primarily consequence of intensive facial growth in this period, not as a effect of used appliances [26]. Angle NSBa was increased during treatment with FR-I and Hotz appliance, while bionator by Balters type I caused decreasing value of angle NSBa. Size, form and structure of cranial base are under genetic control, with some specific characteristics of race and gender. Bones of cranial base are primarily in cartilage. After that enhondral ossification and bone formation begins. Whole cranial base was elongated due to the growth of synhondrosis. We cannot affect the cranial base the same way as the facial bones. Between bones of cranial base are immobile joints, so the whole cranial base appears as one long bone. When we plan orthodontic treatment we can not expect severe changes in morphology and size of cranial base. Present changes were result of intensive displacement and bone remodelation and growth on synhondrosis.

Inclination of upper incisors was changed during orthodontic treatment, angle I/SpP was increased in whole sample. All used appliances caused retrusion of upper incisors, the most visible during treatment with bionator by Balters type I (angle I/SpP was changed from $69.35^{\circ}$ to $71.15^{\circ}$ ). Retrusion of upper incisors is one of the most important dental effects during orthodontic treatment with these appliances. In the beginnig of treatment lower incisors were, mostly retruded or had normoinclination. Position of lower incisors is important information when planning orthodontic treatment. Correct relation between lower incisors and bone jaw base is necessary for stabile therapeutic result [27, 28]. During orthodontic treatment all appliances caused protrusion of lower incisors with decreasing values of angle i/MP. FR-I caused change of this angle from $89.75^{\circ}$ to $88.30^{\circ}$, Hotz appliance from $89.75^{\circ}$ to $87.00^{\circ}$, with statistical significance $\mathrm{p}<0.001$, while bionator by Balters type I decreased value of angle i/MP from $89.15^{\circ}$ to $89.00^{\circ}$, without statistical significance. Balance between retrusion of the upper and protrusion of the lower incisors provides decreasing of overjet.

During orthodontic treatment changes on TMJ were made in two dimensions, the change in a height of TMJ (vertical direction) and anteroposterior position of TMJ (sagittal direction). TMJ is one of growth zones during this period. "Answer" of TMJ to orthodontic treatment is one of the most important facts for final therapeutic result. During orthodontic tretmant the height of TMJ was decreased, without statistical significance. Sagittal position of TMJ was analyzed by distance S-E. This distance was increased during orthodontic treatment, statistically significant during treatment with FR-I (from $22 \mathrm{~mm}$ to $23 \mathrm{~mm}$ ) and bionator by Balters type I $(p=0.042)$. These changes are consequence of used functional appliances and their effects to upper and lower jaw [29, 30]. 
Harmonious facial aesthetics means a balance between skeletal and dentoalveolar structures from one side and structures of soft tissue profile, from the other side. All structures of orofacial complex constitute one indivisible whole. Changes on soft tissue profile were determined using analysis of angles $\mathrm{T}$ and $\mathrm{H}$, position of the upper and lower lip to aesthetic line and height of upper lip. Effects on soft tissue structures are necessary for stabile therapeutic result and good facial aesthetics. During period of growth changes on soft tissues are much more pronounced than on skeletal structures. Upper and lower lip and other soft tissues move down a function of time [31]. As a result of increasing values of angles SNB and SNPg changes in values of angles $\mathrm{T}$ and $\mathrm{H}$ appear. Angle $\mathrm{T}$ is in correlation with angle $\mathrm{J}$ and it was significantly decreased during treatment, from $21.60^{\circ}$ to $17.15^{\circ}$ with FR-I. Angle $\mathrm{H}$ is in correlation with angle ANB. With decreasing of angle ANB decreases the value of angle $\mathrm{H}$. This angle was significantly decreased, most evident when using FR-I from $16.45^{\circ}$ to $13.40^{\circ}, \mathrm{p}<0.001$. Patients with skeletal distal bite have convex profile, with irregular position of the upper and lower lip. During orthodontic treatment upper lip had smaller distance to aesthetic line, when using FR-I from $0.77 \mathrm{~mm}$ to $0.12 \mathrm{~mm}$. Lower lip had, also, smaller distance to aesthetic line, except when using Hotz appliance. During orthodontic treatment height of the upper lip was decreased, when using FR-I from $26.15 \mathrm{~mm}$ to $25.85 \mathrm{~mm}$, while Hotz appliance and bionator by Balters increased height of the upper lip. Decreasing of profile convexity appears as a consequence of movement of the upper and lower lip to Ricketts aesthetic line [32, 33, 34].

Patients with Class II divison 1 often have disturbed orofacial functions, especially swallowing and speech. These patients have infantile swallowing with tongue insertion between upper and lower frontal teeth. FR-I has the greatest impact on correction of orofacial functions [35]. This appliance provides the transition from infantile to mature swallowing. Design of FR-I prevents insertion of lower lip and tongue between upper and lower incisors. It creates conditions for correct articulation of interdental consonants. FR-I causes continuous muscle activation and changes in tone and muscle activity [36, 37, 38].

Pancherz's analysis defines skeletal and dentoalveolar changes during orthodontic treatment. Measurements have been done in the area of upper and lower first permanent molars and incisors and skeletal points pg and ss [39, 40]. FR-I changed molar relation for $1.45 \mathrm{~mm}$, Hotz appliance for $2.12 \mathrm{~mm}$ and bionator by Balters type $\mathrm{I} 1.15 \mathrm{~mm}$. Relation between incisors was changed for $2.05 \mathrm{~mm}$ when using FR-I, $1.85 \mathrm{~mm}$ with Hotz appliance and $1.40 \mathrm{~mm}$ with bionator by Balters type I. Skeletal correction was the most evident when using FR-I 3.35mm, bionator by Balters type I changed it for $2.80 \mathrm{~mm}$ and Hotz appliance for $2.40 \mathrm{~mm}$.

\subsection{Review of clinical effects using FR-III and Y appliance in treatment of skeletal Class III}

Dimensions, position and development of the upper jaw were analyzed using values of angles SNA (angle of maxillary prognatism), SN/SpP (vertical position of the upper jaw to anterior cranial base) and J (angle of facial inclination), and linear distances Cmax which determines the length of the upper jaw. Both appliances had significant effect to the upper jaw, causing her anterior movement in relation to the anterior cranial base and increase the value of the angle SNA, with statistical significance $\mathrm{p}<0.001^{*}$. FR-III caused increasing of SNA angle from $76.65^{\circ}$ to $79.85^{\circ}$, while $\mathrm{Y}$ appliance increased this angle from $76.60^{\circ}$ to $77.90^{\circ}$ Both appliances 
caused increasing of vertical inclination of the upper jaw to the anterior cranial base. This has resulted in increasing values of angle SN/SpP, with FR-III from $10.20^{\circ}$ to $10.50^{\circ}$ and with $\mathrm{Y}$ appliance from $11.75^{\circ}$ to $12.75^{\circ}$. Y appliance caused significant increasing of angle J, from $80.45^{\circ}$ to $81.90^{\circ}$. FR-III, also, caused, an increase in the angle J, but to a much lesser extent, from 83.10 ${ }^{\circ}$ to $83.35^{\circ}$. In the whole sample there was a significant increase in the value of the upper jaw length corpus, with FR-III from $43.24 \mathrm{~mm}$ to $46.15 \mathrm{~mm}$ and with $\mathrm{Y}$ appliance from $46.87 \mathrm{~mm}$ to $48.35 \mathrm{~mm}$. Increasing of maxillary corpus length is a result of simultaneously intensive growth and effect of orthodontic appliance [41, 42, 43]. Position, development and dimension of the lower jaw vere analyzed by angles SNB (angle of mandibular prognatism), SN/MP (angle of vertical position of the lower jaw to the anterior cranial base) and SNPg (sagittal position of chin to the anterior cranial base) and linear parameters: length of mandibular corpus, total length of the lower jaw, height and width of mandibular ramus. Changes in the lower jaw are low, which is in accordance with the design of the appliances, and design of the appliances, and mainly the upper jaw. FR-III increased value of angle SNB from $78.55^{\circ}$ to $78.60^{\circ}$, while Y appliance increased this angle from $79.00^{\circ}$ to $79.45^{\circ}$. Both appliances caused retroinclination of the lower jaw and increasing of angle SN/SpP. FR-III caused changes of SN/MP angle from $35.40^{\circ}$ to $36.65^{\circ}$ and $\mathrm{Y}$ appliance from $36.85^{\circ}$ to $38.90^{\circ}$. Angle SNPg was increased during the treatment, in correlation with increasing of SNB angle. Y appliance caused major changes from $79.45^{\circ}$ to $80.05^{\circ}$, while FR-III increased this angle from $78.80^{\circ}$ to $79.30^{\circ}$. Appliances caused retroinclination of the lower jaw to the anterior cranial base and inhibiting the growth of the lower jaw. All linear parameters were increased, mostly as a result of facial growth. Length of mandibular corpus was increased from $68.85 \mathrm{~mm}$ to $70.00 \mathrm{~mm}$ using FR-III, while Y appliance caused change from $73.55 \mathrm{~mm}$ to $74.75 \mathrm{~mm}$. Total length of the upper jaw was increased with FR-III from $104.05 \mathrm{~mm}$ to $105.60 \mathrm{~mm}$ and with $\mathrm{Y}$ appliance from $118.10 \mathrm{~mm}$ to $118.55 \mathrm{~mm}$. FR-III increased height of mandibular ramus from $52.77 \mathrm{~mm}$ to $53.70 \mathrm{~mm}$, while Y appliance changed this parameter from $54.15 \mathrm{~mm}$ to $54.95 \mathrm{~mm}$. Both appliances increased width of the mandibular ramus, FR-III from $11.55 \mathrm{~mm}$ to $12.55 \mathrm{~mm}$ and $Y$ appliance from $11.15 \mathrm{~mm}$ to $12.10 \mathrm{~mm}$. All effects of appliances resulted in anterior movement of the upper jaw and stimulation of maxillary sagittal and transversal growth [44, 45, 46, 47].

Relationship between upper and lower jaw was determined by values of angles ANB (sagittal interjaw angle, skeletal Class), B or SpP/MP (basal angle - vertical interjaw angle), SpP/OcCP (vertical postion of the upper jaw to occlusal plane) and $\mathrm{MP} / \mathrm{OcCP}$ (vertical position of the lower jaw to occlusal plane). Both appliances caused significant increasing value of ANB angle. It allows correction of skeletal Class III to skeletal Class I. FR-III changed angle ANB from- $1.90^{\circ}$ to $1.25^{\circ}$, while $\mathrm{Y}$ appliance changed this angle from $-2.40^{\circ}$ to $-1.55^{\circ}$, with statistical significance on the level $\mathrm{p}=0.001^{*}$. FR-III primarily affects the skeletal structures due to pelotas which stimulate the growth of the upper jaw, increasing its length and raise the value of ANB angle. Increasing value of ANB angle is a consequence of increasing the value of the angle SNA. Mobile, active appliances mostly affect dentoalveolar structures and skeletal changes are minimal. During the treatment, both appliances increased value of basal angle (B). It can contribute to opening bite. FR-III increased value of angle B from $25.20^{\circ}$ to $26.30^{\circ}$ and $\mathrm{Y}$ appliance changed angle B from $25.05^{\circ}$ to $26.15^{\circ}$. Angle SpP/MP was increased during treatment, with FR-III from $10.30^{\circ}$ to $11.45^{\circ}$ and with $\mathrm{Y}$ appliance from $10.40^{\circ}$ to $11.55^{\circ}$. At the 
same time value of angle $\mathrm{MP} / \mathrm{OcCp}$ was decreased, without statistical significance, with FRIII from $14.90^{\circ}$ to $14.85^{\circ}$ and with $\mathrm{Y}$ appliance from $14.65^{\circ}$ to $14.60^{\circ}$. Changes in basal angle were mostly result of increasing angle between upper jaw and occlusal plane [48, 49]. Appliances are contraindicated in patients with backward facial rotation, because their use can contribute to the bite opening and divergent growth of the bases of upper and lower jaw.

Facial growth and rotation are determined by Björk and Jarabak method. FR-III increased angle NSAr from $122.80^{\circ}$ to $123.87^{\circ}$ and $\mathrm{Y}$ appliance from $127.35^{\circ}$ to $128.65^{\circ}$. Also, both appliances increased value of gonial angle-ArGoMe, FR-III from $131.10^{\circ}$ to $131.85^{\circ}$ and $\mathrm{Y}$ appliance from $131.75^{\circ}$ to $132.15^{\circ}$. FR-III increased value of articular angle-SArGo from $141.50^{\circ}$ to $142.17^{\circ}$, while $\mathrm{Y}$ appliance decreased tih angle from $134.95^{\circ}$ to $134.25^{\circ}$. As a result there is an increase in values of sum of angles of Björks polygon, with FR-III from $395.40^{\circ}$ to $396.90^{\circ}$ and with $\mathrm{Y}$ appliance from $394.05^{\circ}$ to $395.05^{\circ}$. Linear distances, N-Me and S-Go, were increased during this period. This increase was a consequence of pubertal facial growth in this age and use of orthodontic appliances. Relation between anterior and posterior facial height was slightly changed, without influence to total facial growth during the treatment. Relation was changed by FR-III from $64.34 \%$ to $63.35 \%$ and with Y appliance from $63.73 \%$ to $64.30 \%$. If we start with orthodontic treatment early enough we can change the type of facial growth. Generally, FRIII caused slight backward rotation and tendency to the vertical facial growth [50, 51, 52].

FR-III and Y appliance caused increasing of length of anterior cranial base, FR-III from $68.70 \mathrm{~mm}$ to $69.50 \mathrm{~mm}, \mathrm{Y}$ appliance from $71.55 \mathrm{~mm}$ to $72.85 \mathrm{~mm}$. Also, both appliances increased value of total length of cranial base, FR-III from $101.30 \mathrm{~mm}$ to $103.85 \mathrm{~mm}$, Y appliance from $106.85 \mathrm{~mm}$ to $107.45 \mathrm{~mm}$. FR-III caused decreasing of posterior cranial base from $44.55 \mathrm{~mm}$ to $42.70 \mathrm{~mm}$, while $Y$ appliances increased this distance from $47.25 \mathrm{~mm}$ to $47.40 \mathrm{~mm}$. All changes did not have statistically significance. Both appliances caused increase of angle NSBa. Increase was significant during treatment with $\mathrm{Y}$ appliance, which changed this angle from $130.15^{\circ}$ to $131.35^{\circ}$, with statistical significance on the level $\mathrm{p}=0.003^{*}$. Dimension and structure of the cranial base are genetically determined. Changes on the cranial base are not a consequence of orthodontic treatment. Usually changes are results of displacement and remodelation of bones and growth of cranial base [53]. When we plan orthodontic treatment we can not expect severe changes in structures of cranial base.

Position of the upper incisors was analyzed by angle I/SpP. Usually patients with skeletal Class III (except severe mandibular prognatism) have normoinclination of the upper incisors. Both appliances significantly changed value of angle I/Spp, FR-III from $72.70^{\circ}$ to $70.80^{\circ}$ and $\mathrm{Y}$ appliance from $71.30^{\circ}$ to $68.70^{\circ}$, with significance on the level $\mathrm{p}<0.001^{*}$. Y appliance caused, as a mobile active appliance, major changes in dentoalveolar structures. Inclination of the lower incisors was analysed by angle i/MP. FR-III increased value of angle i/MP from $89.50^{\circ}$ to $90.60^{\circ}$, with statistical significance $\mathrm{p}<0.001^{*}$. $\mathrm{Y}$ appliance had no significant effect on the change of value of the angle i/MP (from $90.15^{\circ}$ to $90.05^{\circ}$ ). It was consequence of design of appliance, which is located only on the upper jaw. Protrusion of the upper incisors and retrusion of the lower incisors created conditions for correct overjet [54, 55].

Orthodontic treatment can change vertical position (height of TMJ) and sagittal position of TMJ. TMJ is one of the growth zone during period of puberty. For stabile therapeutic results 
changes on the TMJ structures are very important and their answer to applied force [56]. Both appliances did not have big influence to vertical position of TMJ. FR-III changed height of TMJ from $6.15 \mathrm{~mm}$ to $5.75 \mathrm{~mm}$, while $\mathrm{Y}$ appliance caused change from $4.55 \mathrm{~mm}$ to $4.60 \mathrm{~mm}$. S-E distance was increased during treatment, which is related to the distal movement of TMJ. Y appliance caused greater increasing of S-E distance from $21.90 \mathrm{~mm}$ to $22.65 \mathrm{~mm}$, with statistical significance $\mathrm{p}=0.012^{*}$. FR-III changed S-E distance from $20.40 \mathrm{~mm}$ to $21.25 \mathrm{~mm}$. All changes on TMJ structures are consequence of changes on the upper and lower jaw.

Changes on soft tissue structures were analysed by angles $\mathrm{T}$ and $\mathrm{H}$, position of the upper and lower lip to aesthetic line and height of the upper lip. Angle $\mathrm{T}$ is in correlation with angle J. Changes of angle J during the treatment caused increasing value of angle $\mathrm{T}$ in patients with skeletal Class III. FR-III increased angle T from $7.05^{\circ}$ to $10.50^{\circ}$, while $\mathrm{Y}$ appliance increased this angle from $8.80^{\circ}$ to $10.70^{\circ}$. Angle $\mathrm{H}$ (Holdaway) is in positive correlation with angle ANB. Patients with skeletal Class III have angle $\mathrm{ANB}<2^{\circ}$. Orthodontic treatment increase value of ANB angle and, at the same time, increase of angle $\mathrm{H}$. FR-III changed angle $\mathrm{H}$ from $5.35^{\circ}$ to $8.25^{\circ}$ and $\mathrm{Y}$ appliance from $6.60^{\circ}$ to $7.85^{\circ}$, both with statistical significance $\mathrm{p}<0.001^{*}$. Patients with pseudo skeletal Class III have typical concave profile, with back position of the upper jaw. That is why upper lip is significantly posteriorly moved to the aesthetic line. FR-III approach upper lip to the aestetic line and changed distance from- $5.15 \mathrm{~mm}$ to- $1.80 \mathrm{~mm}$. Y appliance, also, change sagittal position of the upper lip and decreased distance to the aesthetic line from- $4.85 \mathrm{~mm}$ to- $3.45 \mathrm{~mm}$. In the whole sample lower lip was significantly back to the aesthetic line. Both appliances affect the movement of the lower lip to the aesthetic line. Y appliance changed position of the lower lip from- $0.80 \mathrm{~mm}$ to $0.30 \mathrm{~mm}$ and FR-III changed distance of the lower lip to the aesthetic line from $-1.25 \mathrm{~mm}$ to- $-0.80 \mathrm{~mm}$. Patients with pseudo Class III have underdeveloped upper jaw and reduced height of the upper lip. Orthodontic treatment stimulated sagittal growth of the upper jaw. This allows changes in soft tissue profile and increasing the height of the upper lip. FR-III caused increasing of height of the upper lip from $21.75 \mathrm{~mm}$ to $23.45 \mathrm{~mm}$, while $\mathrm{Y}$ appliance increased this parameter from $21.60 \mathrm{~mm}$ to $22.30 \mathrm{~mm}$. Changes of position of the upper and lower lip and increasing of height of the upper lip contributes to the reduction of profile concavity $[57,58,59]$. During the period of puberty growth, changes on soft tissues are much more pronounced than on skeletal structures. Upper and lower lip and other soft tissues move down a function of time. It is important to choose the best possible treatment procedure if we want to achieve a good relationship between soft tissue and bone structures. It is important to analyse value of nasolabial angle. In patients with decreased nasolabial angle orthodontic treatment has to achieve posterior movement of the upper jaw. In cases with increased value of nasolabial angle, it is necessary to move nasomaxillary complex forward during orthodontic treatment. Orthodontic treatment caused decrease of profile concavity, increasing of height and thickness of the upper lip and anterior movement of the upper lip to the aesthetic line [60].

Patients with skeletal Class III often have infantile swalowing with anterior tongue position and oral respiration. Speech is orofacial function which last develops during individual maturation. Patients with skeletal Class III have reverse overjet. That is why articulation of interdental and labial consonants is incorrect. FR-III equally successfully corrects morpholog- 
ical and functional differences and contributes the correct performance of orofacial functions. FR-III significantly affects the function of swallowing and contributes to the transition from infantile to mature swallowing. In this sample (treated with FR-III) before treatment 12 patients had infantile swallowing, while 8 patients had mature swallowing. After orthodontic treatment with FR-III 13 patients had mature swallowing, while 7 had infantile swallowing. Design of FR-III prevents tongue insertion between upper and lower incisors. FR-III change activity and tongue position and it contributes changes in the function of swallowing [61]. Y appliance did not have influence on changing of swallowing function. FR-III improves articulation of interdental cionsonants, due to activity of lip muscles and changing of upper incisors inclination. Before orthodontic treatment 8 patients had correct speech and 12 patients had incorrect speech. After orthodontic treatment with FR-III 14 patients had correct speech, while 6 patients had incorrect speech. FR-III changes activity of muscles and eliminates incorrect relation between upper and lower lip.

Pancherz's analysis explained changes on dental and skeletal structures. FR-III corrected molar relation for $3.25 \mathrm{~mm}$ and $\mathrm{Y}$ appliance for $2.35 \mathrm{~mm}$. Relations between incisors were changed for $2.40 \mathrm{~mm}$ when using FR-III and for $2.10 \mathrm{~mm}$ when using $\mathrm{Y}$ appliance. Skeletal correction was more effective when using FR-III, for $3.30 \mathrm{~mm}$, while Y appliance caused skeletal correction for $1.40 \mathrm{~mm}$. FR-III caused skeletal correction according to stimulating of osteoblasts in periost and intensive sagittal growth of the upper jaw [62, 63, 64]. Mobile appliance caused primarily dental correction, while skeletal changes were irrelevant. Dental effects were manifested as correction of reverse overjet due to protrusion of the upper and retrusion of the lower frontal teeth.

\section{Conclusion}

FR-I is the most effective functional appliance in early treatment of skeletal distal bite. This appliance corrects occlusal morphology, orofacial functions and facial aesthetics. Main skeletal effects of FR-I are:

- anterior displacement and stimulation of sagittal growth of the lower jaw

- suppression of the sagittal growth of the upper jaw

- significantly increasing of length of mandibular corpus and ramus

- decreasing value of ANB angle and correction of skeletal Class II to Class I

- decreasing of vertical interjaw angle

- elimination of the pressure, application of pressure, application of pulling force and continuous activation of orofacial muscles

- increasing of sum of angles of Björk polygon and moderate backward rotation

The main dental effects of FR-I are:

- retrusion of the upper incisors 
- protrusion of the lower incisors

- rotation of the occlusal plane

- mesial movement of lower posterior teeth

- distal movement of upper posterior teeth

This appliance is very comfortable for wearing, does not affect the function of speech, patients are motivated to cooperate. Treatment is very efficient, therapeutic results are stabile and tendency to relapse is minimal. That's why FR-I is the most appropriate appliance for successful early treatment of Class II divison 1 malocclusion.

Also, FR-III is one of the best choice for early orthodontic treatment of skeletal Class III caused by maxillary retrognatism. This functional appliance affects occlusal morphology, orofacial functions and facial aesthetics. In all segments FR-III is much more efficient in comparing with Y mobile appliance. Effects of this appliance are the result of stimulating of sagittal and transversal growth of the upper jaw, inhibition of growth of the lower jaw, elimination of the pressure, aplication of the pressure, tensile stress force and continuous activation of orofacial muscles. Pseudo Class III is severe skeletal problem which is transferred from the deciduous dentition to mixed and permanent dentition. If we use FR-III in early mixed dentition we avoid the use of other functional appliances during puberty growth. First therapeutic results appear after 3 to 6 months from the beginning of treatment, results are stabile, without signs of relapse, with correct protocol of wearing. The main disadvantages of this appliance are complicated preparation in dental laboratory, gracile structure, inability to repair appliance and a long duration of orthodontic therapy. The main advantages of this appliance are the possibilities of application at an early age, correction of functional and occlusal irregularities at the same time, the patient's motivation, good cooperation and comfort.

The main skeletal effects of FR-III are:

- stimulation of sagittal growth of the upper jaw

- increasing of vertical angle between upper jaw and anterior cranial base

- significant increase of length of maxilarry corpus

- inhibition of sagittal growth of the lower jaw

- increasing of vertical angle between lower jaw and anterior cranial base

- increasing value of ANB angle and correction skeletal Class III to Class I

- increasing of basal angle (B)

- increasing of sum of angles of Björk polygon and moderate backward rotation

The main dental effects of FR-III are:

- protrusion of the upper incisors

- retrusion of the lower incisors 
- rotation of the occlusal plane

- distal movement of lower posterior teeth

- mesial movement of upper posterior teeth

Dental effects allow correction of reverse overjet and achieve proper overjet and correction of molar relations.

FR-III significantly alters the activity of orofacial muscles and affects the correction of swallowing and speech functions. Treatment with FR-III contributes to achieving better facial aesthetics and establishing harmony between the soft and hard tissues of the craniofacial complex.

We can recommend this functional appliance for everyday clinical practice and successful early treatment in patients with skeletal distal and mesial (pseudo Class III) bite.

\section{Author details}

Zorana Stamenković* and Vanja Raičković

*Address all correspondence to: zzokac@yahoo.com

Department of Orthodontics, Faculty of Dentisty, University of Belgrade, Serbia

\section{References}

[1] Dodić S.: Analiza morfologije i funkcije orofacijalnog kompleksa u adolescenata sa kraniomandibularnim disfunkcijama. Doktorska teza. Beograd, 2003.

[2] Battagel J.: The aetological factors in Class III malocclusion. Eur. J. Orthod. 1993; 15: 347-370.

[3] Mc Guigan D. G.: The Hapsburgs. London. WH Allen. 1966.

[4] Bishara SE. Textbook of orthodontics. W. B. Saunders; Philadelphia, 2001.

[5] O'Relly T., Yanneillo G.: Mandibular growth changes and maturation of cervical vertebrae - A longitudinal cephalometric study. Angle Orthod. 1988; 4: 179-184.

[6] Ball G, Woodside D, Tompson B, Hunter WS, Posluns J. Relationship between cervical vertebral maturation and mandibular growth. Am J Orthod Dent Orthop 2011; 139 (5): 455-461.

[7] Proffit W.B. Fields H. W., Sarver D. M.: Contemporary orthodontics. The Mosby Co. St: Louis, 2007. 
[8] Almeida M. R., Henriques J. F. C., Almeida R. R., Almeida-Pedrin R. R., Ursi W.: Treatment effects produced by the Bionator appliance. Comparison with an untreated Class II sample. Eur. J. Orthod. 2004; 26: 65-72.

[9] Carlos Flores-Mir and Paul W. Major: A systematic review of cephalometric facial soft tissue changes with the Activator and Bionator appliances in Class II division 1 subjects. Eur. J. Orthod. 2006; 28: 586-593.

[10] Faltin K. J., Faltin R. M., Baccetti T., Franchi L., Ghiozzi B., McNamara J. A. Jr.: Longterm effectiveness and treatment timing for Bionator therapy. Angle Orthod. 2003; 73 (3): 221-230.

[11] Hotz R.: Orthodontics in daily practice. Bern, Switzerland, Huber. 1974.

[12] Isaacson K. G., Muir J. D., Reed R. T. Removable orthodontic Appliances, Oxford, 2002.

[13] Fränkel R., Fränkel Ch.: Orofacial Orthopaedics with the Function Regulator. Karger, Basel - Munchen -Paris - London - New York - New Delhi - Singapore - Tokyo Sydney, 1989.

[14] Fränkel R.: Funktionskieferorthopadie und der Mundvorhof als Papparatus Basis, VEB Verl., Berlin, 1967.

[15] Fränkel R.: A functional approach to orofacial orthopaedics. Br. J. Orthod. 1980; 7: 41-51

[16] Kanas R. J., Carapezza L., Kanas S. J.: Treatment Clasification of Class III Malocclusion. The Journal of Clinical Pediatric Dentistry. 2008; 33(2): 175-186.

[17] Baik H. S., Jee S. H., Lee K. J., Oh T. K.: Treatment effect of Frankel functional regulator III in children with class III malocclusions. Am. J. Orthod. Dentofacial Orthop. 2004; 125: 294-301.

[18] Stamenković Z.: Klinički efekti primene Fränkel-ovih regulatora funkcije u terapiji distalnog i mezijalnog zagrižaja. Doktorska disertacija. Beograd, 2011.

[19] Almeida M. R., Henriques J. F. C. and Ursi W.: Comparative study of the Frankel (FR-2) and bionator appliances in the treatment of Class II malocclusion. Am. J. Orthod. Dentofacial Orthop. 2002; 121: 458-466.

[20] Araujo A. M., Buschang P. H., Melo A. C. M.: Adaptive condylar growth and mandibular remodeling changes with bionator therapy - an implant study. Eur. J. Orthod. 2004; 26: 515-522.

[21] Chen J. Y., Will L., Neiderman R.: Analysis of efficacy of functional appliances on mandibular growth. Am. J. Orthod. Dentofacial orthop. 2002; 122: 470-476. 
[22] Yamin-Lacouture C., Woodside D.G., Sectakof P.A., Sessle B.J.: The action of three types of functional appliances on the activity of the masticatory muscles. Am. J. Orthod. Dentofacial Orthop. 1997; 112: 560-572.

[23] Martins R. P., Martin J. C., Martins L. P., Buschang P. H.: Skeletal and dental components of Class II correction with the bionator and removable headgear splint appliances. Am. J. Orthod. Dentofacial Orthop. 2008; 134: 732-741.

[24] Chadwick S.M., Aird C., Taylor S., Bearn D.R.: Functional regulator treatment of Class II division 1 malocclusions. Eur. J. Orthod. 2001; 23: 495-505.

[25] Barton S., Cook P. A.: Predicting functional appliance treatment outcome in Class II malocclusions - a rewiew. Am. J. Orthod. Dentofacial Orthop. 1997; 112: 282-286.

[26] Cevidanes L. et al: Clinical outcomes of Fränkel appliance therapy assessed with a counterpart analysis. Am. J. orthod. Dentofacial Orthop. 2003; 123: 379-387.

[27] Moreira Melo A. C., dos Santos-Pinto A., da Rosa Martins J. C., Martins L. P., Sakima M. T.: Orthopedic and orthodontic components of Class II, division 1 malocclusion correction with Balters Bionator: A cephalometric study with metallic implants. World J. Orthod. 2003; 4: 273-242.

[28] Rodrigues de Almeida M., Castanha Henriques J. F., Rodrigues de Almeida R., Ursi W.: Treatment effects produced bz Fränkel appliance in patients with Class II, division 1 malocclusion. Angle Orthod. 2002; 72 (5): 418-425.

[29] Falck F., Fränkel R.: Clinical relevance of step-by-step mandibular advancement in the treatment of mandibular retrusion using the Fränkel appliance. Am. J. Orthod. Dentofacial Orthop. 1989; 96: 333-341.

[30] Thieme KM, Nägerl H, Hahn W, Ihlow D, Kubein D. Variations in cyclic mandibular movements during treatment of Class II malocclusions with removable functional appliances. Eur J Orthod 2011: 33(6): 628-635.

[31] Patel H. P., Moseley H. C., Noar J. H.: Cephalometric determinants of successful functional appliance therapy. Angle Orthod. 2002; 72: 410-417.

[32] Battagel J. M.: Profile changes in Class II, division 1 malocclusions: a comparison of the effects of Edgewise and Fränkel appliance therapy. Eur. J. Orthod. 1989; 11: 243-253.

[33] Battagel J. M.: The relationship between hard and soft tissue changes following treatment og Class II division 1 malocclusions using Edgewise and Fränkel appliance techniques, Eur. J. Orthod. 1990; 12: 154-165.

[34] [34]Quintao C., Helena I., Brunharo V. P., Menezes R. C., Almeida M. A. O: Soft tissue facial profile changes following functional appliance therapy. Eur. J. Orthod. 2006; 28: 35-41. 
[35] Creekmore T. D., Radney L.J.: Frankel appliance therapy: orthopedic or orthodontic? Am. J. Orthod. 1983; 83:89-108.

[36] Janson G.R.P., Alegria Toruno J.L., Rodrigez Martins D., Henriques J.F.C., de Freitas M.R.: Class II treatment effects of the Fränkel appliance. Eur. J. Orthod. 2003; 25: 301-309.

[37] Read M. J. F.: The integration of functional and fixed appliance treatment. Am. J. Orthod. 2001; 28 (1): 13-18.

[38] Woodside D. G.: Do functional appliances have an orthopedic effect? Am. J. Orthod. Dentofacial Orthop. 1998; 113:11.

[39] Pancherz H., Zieber K., Hoyer B.: Cephalometric characteristics of Class II division 1 and Class II division 2 malocclusions: a comparative study in children, Angle Orthod. 1997; 67: 111-120.

[40] Rushforth C. D., Gordon P. H., Aird J. C.: Skeletal and dental changes following the use of the Frankel funkcional regulator. Br. J. Orthod. 1999; 26:127-134.

[41] Bacetti T. et al.: Skeletal effects of early treatment of Class III malocclusion. Am. J. Orthod. Dentofac. Orthop. 1998; 113: 333 - 343.

[42] Levin A. S., McNamara J. A. Jr., Franchi L., Baccetti T., Frankel C.: Short-term and long-term treatment outcomes with the FR-3 appliance of Frankel. Am. J. Orthod. Dentofacial Orthop. 2008; 134: 513-524.

[43] Miethke R. R., Lindenau S., Dietrich K.: The effect of Fränkel's function regulator type III on the apical base. Eur. J. Orthod.2003; 25: 311-318.

[44] Negi A., Singla A., Mahajan V.: Effects of Maxilarry Protraction And Frankel Appliance Therapy On Craniofacial Structures And Pharyngeal Airway. Indian Journal of Dental Sciences. 2013; 5(5): 30-33.

[45] Pangrazio-Kulbersh V., Berger J., Kersten G.: Effects of protraction mechanics on the midface. Am. J. Orthod. Dentofacial Orthop. 1998; 114: 484-491.

[46] Seehra J., Fleming P. S., Mandall N., DiBiase A. T.: A comparison of two different techniques for early correction of Class III malocclusion. The Angle Orthodontist. 2012; 82(1): 96-101.

[47] Fränkel R: Maxillary retrusion in Class III and treatment with the functional corrector III. Trans. Eur. Orthod. Soc. 1970; 46: 249-259.

[48] Almeida M. R., Almeida R. R., Oltramari-Navarro P. V., Conti A. C., Navarro R de L, Camacho J. G.: Early treatment of Class III malocclusion: 10-year clinical follow-up. J Appl Oral Sci.: 2011; 19: 431-439.

[49] Zentner A., Doll G. M., Peylo S. M.: Morphological parameters as predictors of successful correction of Class III malocclusion. Eur. J. Orthod. 2001; 23: 383-392. 
[50] Santos-Pinto A. D., Paulin R. F., Moreira Melo A. C.: Pseudo-Class III treatment with reverse traction: case report. Journal of Clinical Pediatric Dentistry. 2001; 25 (4): 264-274.

[51] Ulgen M., Firatli S.: The effects of Fränkel's function regulator on the Class III malocclusions. Am. J. Orthod. 1994; 105: 561-567.

[52] Oltramari-Navarro P. V. P., Almeida R. R., Conti A. C., Navaro R de L. et al: Early treatment Protocol for Skeletal Class III Malocclusion. Brazilian Dental Journal. 2013; 24(2): 167-173.

[53] Toffol L. D., Pavoni C., Bacceti T., Franchi L. and Cozza P.: Orthopedic treatment outcomes in Class III malocclusion. The Angle Orthod. 2008; 78: 561-573.

[54] Giancotti A., Maselli A., Mampieri G. and Spano E.: Pseudo-Class III malocclusion treatment with Balters' bionator. Br. Orthodontic Soc. 2003; 30 (3): 203-215.

[55] Loh M. K., Kerr W. J. S.: The function regulator III: effects and indications for use. Br. J. Orthod. 1985; 12: 153-157.

[56] Kapur A., Chawla H. S., Utreja A., Goyla A.: Early Class III occlusal tendency in children and its selective management, Journal of the Indian Society of Pedodontics and Preventive Dentistry. 2008; 26 (3): 107-113.

[57] Stamenković Z., Nedeljković N.: Karakteristike mekotkivnog profila kod pacijenata sa III skeletnom klasom. Stomatološki glasnik Srbije, 2006. Vol. 53, 166-173.

[58] Zhao G., Sha L., Chang B.: Soft tissue profile changes by Frankel-III appliance on correcting Angle Class III malocclusion in mixed dentition. Shanghai Journal of Stomatology. 2011; 20(2): 201-203.

[59] Kerr W. J., Ten Have T. R.: Changes in soft tissue profile during the treatment of Class III malocclusion. Br. J. Orthod. 1987; 14(4): 243-249.

[60] Prashanth C. S., Dinesh M. R., Akshai Shetty K. R.: Class III - Three way approach, a review of contemporary treatment modalities. Journal of International Oral Health. 2010; 2(1): 27-30.

[61] Robertson N. R. E.: An examination of treatment changes in children treated with the function regulator of Frankel. Am. J. Orthod. 1983; 83: 299-310.

[62] Chen F., Terada K., Wu L., Saito I.: Longitudinal evaluation of the intermaxilarry relationship in Class III malocclusions. Angle Orthod. 2006; 76: 955-961.

[63] Standt C. B., Kiliaridis S.: Different skeletal types underlying Class III malocclusion in a random population. Am J Orthod Dentofacial Orthop. 2009; 136: 715-721.

[64] Zentner A., Doll G. M.: Size discrepancy of apical bases and treatment success in Angle Class III malocclusion. Journal of Orofacial Orthopedics 2001; 62: 97-106. 